\title{
NECESSIDADE DA LEITURA NO PROCESSO ENSINO/APRENDIZAGEM
}

\author{
Selma Maria Siqueira Farias ${ }^{1}$ \\ Marcel Pereira Pordeus ${ }^{2}$
}

RESUMO: Este artigo faz parte da minha pesquisa de mestrado, ao qual aglutinei alguns saberes juntamente com outros pesquisadores para formação de embasamento teórico. Nesse sentido, este trabalho objetiva num primeiro momento levantar dados bibliográficos que visem comprovar as implicações do processo de construção da leitura e consequentemente da escrita nos altos índices de repetência nas séries iniciais do ensino fundamental. A forma como aprendemos a ler na infância determina os usos que lhe damos na idade adulta. Se a ênfase é dada apenas à parte mecânica, será difícil, para o aprendiz perceber a gama de possibilidades e significados, julgando a leitura um meio para fins restritos. A leitura exerce um papel fundamental não só na pré-escola, mas também nas demais etapas do processo escolar pela parcela de responsabilidade na formação do leitor. A falta de leitura provoca problemas graves na expressão escrita, dificultando o ensino-aprendizagem, por exemplo, da redação. O hábito de leitura, contudo, só consegue ter êxito se associado ao prazer, ao jogo e à arte, de modo que o leitor se sinta motivado em contato com formas de comunicação que caracterizam a arte da palavra.

Palavras-chave: Leitura. Ensino/Aprendizagem. Ensino Fundamental.

\section{INTRODUÇÃO}

O processo de ensino aprendizagem da leitura é sem dúvida, muito instigante e desafiador, tanto para o aluno como para o professor. Adquirir a capacidade de ler significa, sobretudo a condição de compreender um mundo que vai se mostrando cada vez maior e mais surpreendente. São nessas descobertas que alguns alunos apresentam mais dificuldades do que os outros.

$\mathrm{O}$ interesse pelo tema "Necessidade da leitura no processo ensino aprendizagem" surgiu durante a observação que venho fazendo ao longo de minha carreira, através da qual tenho percebido que a maioria dos alunos ainda não tem consciência da importância, da necessidade da leitura em seu processo de aprendizagem, isto é, na maioria

\footnotetext{
I Professora e mestra em Ciências da Educação pela Universidad Interamericana. E-mail: ceumare@yahoo.com.br

${ }^{2}$ Professor e mestre em Planejamento e Políticas Públicas pela UECE. E-mail: marcel.pordeus@aluno.uece.br
} 
das vezes leem por obrigação, leem somente o que lhe é determinado, sem dar à leitura seu valor real, sem perceber a necessidade de ler; ler para buscar informações, conhecimentos, para enriquecer seu vocabulário, para visualizar palavras e perceber sua ortografia. Esse desconhecimento sobre a importância e a necessidade da leitura torna-se um entrave no processo de desenvolvimento do aluno, uma vez que ele não a vê como algo prazeroso, não se sente motivado a ler diariamente e espontaneamente, abandonando chances de vivenciar ricas experiências de enriquecimento.

Nas escolas do meio rural, sem biblioteca e o ambiente familiar que não estimula a formação de leitores, uma vez que os alunos são originados de famílias de renda baixa e pais analfabetos ou semianalfabetos, hoje verifico que não é só o ambiente que influencia, a realidade mostra que na zona urbana, onde há geralmente onde há uma biblioteca, um ambiente alfabetizador e estimulador muito maior, e o problema é o mesmo: os alunos não dão apreço à leitura. Segundo Murilo Avellar Hingel, ex-secretário da educação de Minas Gerais: "A leitura pode nos conduzir por tempo, lugares e acontecimentos que não são os nossos. A leitura é necessária para a construção da cidadania, para a formação de homens livres e aptos a participar da grande obra que é a humanidade" (LIÇOES DE MINAS, 1999).

A educação recebe atualmente uma expressiva atenção por parte dos governos. A erradicação do analfabetismo tornou-se um ícone do desenvolvimento e, por isso, uma forma de melhorar a imagem do país frente aos bancos internacionais. Para tanto, investem pesado, esforçam-se em matricular o maior número possível de crianças e evitar a evasão. Nos países da América Latina, quase todos possuem mais de 70\% de sua população infantil nas primeiras séries do Ensino Fundamental. No Brasil programas como Bolsa Escola dão ajuda financeira às famílias das crianças carentes para que mantenham uma frequência escolar superior a $75 \%$. Com certeza essas medidas contribuem para a diminuição do analfabetismo, mas o que se observa é que estes números são parte de um discurso oficial que leva em consideração àqueles que apenas fazem a decodificação de sinais gráficos, mas não entendem a necessidade de ler (LIÇOES DE MINAS, 1999).

Nos anos 6o afirmavam categoricamente que o mundo da escrita daria lugar ao mundo da imagem. Mas o que se viu nesses quarenta anos aponta em outra direção. Ser 
usuário competente da linguagem, leitura e escrita é cada vez mais condição para efetiva participação social. Diante disso percebemos que, o domínio instrumental da leitura é necessário para garantir ao aluno autonomia no contato com o texto como fonte de lazer e enriquecimento. Qual é a necessidade da leitura no ensino - aprendizagem? Por que os alunos não leem espontaneamente? Qual é a dificuldade dos alunos em ter o hábito de ler? Compreendem a leitura como meio de formação e informação? A partir destes questionamentos é que se propõe a pesquisar sobre a necessidade e dificuldades da leitura no ensino - aprendizagem.

A presente pesquisa poderá servir de orientação para discussões de docentes sobre a importância da leitura no cotidiano do ser humano. O tema da pesquisa foi escolhido devido a constatações em nossa prática cotidiana, tendo em vista o grande índice de alunos repetentes nas séries iniciais, por não apresentarem conhecimentos mínimos necessários para a sua aprovação, visto que é cobrado cada vez mais a capacidade de interação e integração no meio social a qual o indivíduo encontra-se inserido. Formar leitores faz o processo de emancipação de um país, e o ato da leitura e da escrita conduz a um processo de aprender, de conhecer, de apreender novos significados que ajuda aos educandos a viverem com mais plenitude. Um dos primeiros passos nesse sentido é a oferta de uma educação que esteja próxima à realidade de cada educando, que suscite sugestões e ações significativas para a sua vida.

Importante se faz a construção de relações de confiança entre professor e aluno, pois são aspectos que se constituem num estímulo para que o educando possa perceber-se como cidadão e, como ser social e histórico. O professor precisa reconhecer e valorizar a diversidade cultural dos alunos, superar discriminações, trabalhar a autoestima consciente de que poderá estar revertendo um dos mais fortes mecanismos de exclusão social, a marginalização pela negação do direito ao domínio da cultura escrita, cumprindo assim uma tarefa essencial para a promoção da cidadania.

Toda instituição escolar tem características que lhe são peculiares, e que influenciam o comportamento de seus membros. Essa influência, tanto pode ser para a dominação como para a libertação, dependendo do nível de consciência despertado pelo processo vivido. Tendo essa visão sobre a educação, buscou-se compreender: Quais as implicações no processo de aprendizagem da leitura e da escrita na repetência nas séries 
iniciais? Diante dessa proposta, a pesquisa teve como objetivo compreender a partir da visão de teóricos que abordam a questão, as implicações do processo de aprendizagem da leitura e da escrita na repetência nas séries iniciais. Para isso buscou-se uma bibliografia contextualizada e pertinente ao assunto, buscando identificar aspectos subjacentes à prática que são apontados como facilitadores ou não do crescimento do aluno em relação a leitura e a escrita.

\section{O DESEMPENHO DA LEITURA NO BRASIL}

A realidade no Brasil nos mostra que educadores e alunos não tem a prática de leitura. As avaliações externas demonstram esse cenário e que é muito preocupante, pesquisas realizadas pela "Câmara Brasileira do Livro", em conjunto com a "Fundação Victor Cevita" mostrou que dos brasileiros de II a 64 anos 61\% têm muito pouco ou nenhum contato com os livros e a quantidade de livros lidos por pessoa ao ano é insignificante no Brasil, apenas I,8 livros, enquanto que na França são lidos 7 livros por pessoa ao ano; nos Estados Unidos 5, I livros ao ano, na Itália são lidos 5 livros ao ano e na Inglaterra 4,9 livros ao ano.

Nos últimos anos, o baixo nível de rendimento em prática de leitura no Brasil tem sido uma constante preocupação por parte de educadores e instituições de ensino, tanto que recentemente o Ministério da Educação lançou o prêmio "Vivaleitura", com o objetivo de estimular pessoas e instituições de ensino a desenvolverem projetos que incentivem a prática de leitura (BRASIL, 200I). Também, escritores e educadores como Paulo Freire em sua obra "O Ato de ler", Carlos Humberto em seu livro "Leitura na Universidade", Maria Helena Martins em sua obra "O Que é leitura”, além de revistas, artigos e outros trabalhos que ressaltam sobre a importância da prática de leitura.

Isso demonstra que o país, com todos os seus programas e projetos sobre leitura, não está ainda preparado para capacitar os alunos a obterem um melhor desempenho em suas atividades educacionais, principalmente no que diz respeito à leitura. Também, a maioria dos alunos do $6^{\circ}$ ao $9^{\circ}$ ano do ensino fundamental das escolas brasileiras vem recebendo constantes críticas por parte dos professores e educadores, que dizem terem observado grandes dificuldades por parte dos alunos em ler e interpretar textos. Isso está ocorrendo porque os saberes pedagógicos necessários para estimular a 
prática de leitura atualmente não têm sido suficientes para resolver o problema. Assim sendo, precisa-se criar com urgência, novos saberes pedagógicos de estímulos à prática de leitura.

Ao contrário da escrita, que é uma atividade de exteriorizar o pensamento, a leitura é uma atividade de assimilação de conhecimento, de interiorização, de reflexão. Por isso, a escola que não lê muito para os seus alunos e não lhes dá a oportunidade de ler muito está fadada ao insucesso e não sabe aproveitar o melhor que tem para oferecer aos seus alunos.

Nos estudos sobre a formação de leitores no ambiente escolar, uma quantidade significativa de professores de $\mathrm{I}^{\circ}$ grau se mostra insatisfeitos em razão do tipo de envolvimento dos alunos com a leitura, sentindo-se, muitas vezes, sem subsídios, para refletir sobre suas práticas cotidianas e, a partir daí, modificá-las. Em primeiro lugar, constatam-se condições de (des)conhecimento, por parte de professores e bibliotecários, quanto à variedade e à qualidade textual de obras de literatura com as quais os alunos poderiam se envolver. Em segundo lugar, revelam-se atos de leitura decorrentes talvez dessas primeiras condições: um trabalho muitas vezes mecânico, controlador, punitivo e, por conseguinte, pouco agradável e pouco frutífero com o texto literário na escola. Estas atitudes do professor seguida da falta de vontade dos alunos, dificulta o desenvolvimento do hábito de ler.

Magda Soares (2001, online), em uma entrevista para a TV Escola faz a seguinte citação: "Mais do que nunca, e não só os livros, mas também revistas, jornais, outdoors, contratos, contas, notas fiscais, é preciso aprender ler, não só como meio, mas como objeto de conhecimento". Torna-se necessário ler, não simplesmente para extrair informações da escrita, decodificando-a, letra por letra, palavra por palavra, e sim para compreender o sentido da escrita.

De acordo com os PCN (1998)

A leitura é um processo no qual o leitor realiza um trabalho ativo de construção do significado do texto, a partir de seus objetivos, do seu conhecimento sobre o assunto, sobre o autor, de tudo o que sabe sobre a língua: características do gênero, do portador, do sistema de escrita (p. 94). 
Dessa forma, é fundamental compreender as ações que se processam na mente dos alunos quando estes estão tentando absorver os símbolos gráficos e souber quais estratégias utilizar para auxiliá-lo no ato de ler e escrever. Nessa oportunidade surge a psicopedagogia capaz de oferecer alternativas de ação no sentido de uma transformação, o que possibilita a escola e os alunos uma melhoria nas condições de aprendizagem.

Segundo Paulo Freire: "A leitura do mundo precede sempre a leitura da palavra" (FREIRE, 1988, p. 32). Baseando-se na visão de Freire, entendemos que a sociedade brasileira, que emerge neste novo milênio como uma nação que vem discutindo e enfrentando variados problemas de maneira dinâmica e criadora, deverá para ampliar e consolidar suas conquistas, desejar e buscar todos os meios possíveis para vir a ser uma sociedade de cidadãos autônomos, críticos, capazes de compreender a realidade do mundo.

De acordo com Paulo Freire:

\begin{abstract}
$\mathrm{Na}$ comunidade da leitura vai cabendo ao leitor ou leitora o exercício de perceber se este ou aquele saber referido corresponde à natureza da pratica progressiva ou conservadora ou se, pelo contrário, é exigência da pratica educativa mesma independentemente de sua cor política ou ideológica (FREIRE, 2005, p. 2I).
\end{abstract}

Segundo Maria Helena, “[...] temos, então, mais um motivo para ampliar a noção de leitura. Vista num sentido amplo, independente do contexto escolar, e para além do texto escrito, permite compreender e valorizar melhor cada passo do aprendizado das coisas, cada experiência” (MARTINS, 1993, p. 29).

Observando a perspectiva de Paulo Freire, no sentido de leitura para além da decodificação, encontramos um exemplo de preocupação pedagógica, envolvido pela realidade social dramática e desafiadora de sua terra natal (o Nordeste), Freire estudou e desenvolveu algumas reflexões pedagógicas, históricas, culturais e filosóficas importantes a respeito da leitura.

Para Freire, é uma profunda injustiça haver homens e mulheres que não sabem ler e escrever. Isto porque os analfabetos se veem anulados por sua incapacidade de tomar decisões, de compreender a realidade do mundo. Freire vê a leitura, assim como a educação, como um ato político; como uma tomada de consciência da posição do individuo membro de uma sociedade, compreendendo as relações políticas que existem nela e seu papel diante dessas relações. Tomando consciência da sua experiência, da sua leitura de 
mundo, o individuo compreende seus limites e seu potencial dentro da sociedade. É o que podemos perceber na seguinte citação: "Ser capaz de nomear a própria experiência é parte do que significa ler o mundo e começar a compreender a natureza política dos limites bem como das possibilidades que caracterizam a sociedade mais ampla” (FREIRE, 1990, p. 7-8).

A leitura, na visão de Freire, torna-se algo significativo na medida em que é encarada como um conjunto de praticas que funcionam para desenvolver a potencialidade do sujeito; ou seja, a leitura pode ser encarada como um conjunto de praticas culturais, esportivas, que podem promover mudanças sociais. Freire acreditava que uma leitura critica não poderia deixar de lado as relações entre o econômico, o social, o cultural, o político e o pedagógico, para que o aluno possa tomar consciência de si, da sociedade e a partir de então, agir sobre ela.

$\mathrm{O}$ ato de aprender a ler e escrever é um ato criativo que implica uma compreensão critica da realidade. $\mathrm{O}$ conhecimento de um conhecimento anterior, obtido pelos educandos como resultado da análise de práxis em seu contato social, abre para eles a possibilidade de um novo conhecimento. O novo conhecimento revela a razão de ser que se encontra por detrás dos fatos, desmitologizando, assim, as falas interpretações desses mesmos fatos. Desse modo, deixa de existir qualquer separação entre pensamentolinguagem e realidade objetiva. "A leitura de um texto exige agora uma leitura dentro do contexto social a que ele se refere" (FREIRE, I990, p. I05).

\section{I Processo de construção da leitura e escrita significativa}

A importância de formar leitores tem a sua relevância no processo de aprendizagem e de estímulo a consciência crítica do homem frente a sociedade em que vivemos. Formar leitores faz o processo de emancipação de um país, e o ato da leitura e da escrita conduz a um processo de aprender, de conhecer, de aprender novos significados que ajuda aos educandos a viverem com mais plenitude. Um dos primeiros passos nesse sentido é a oferta de uma educação que esteja próxima à realidade de cada educando, que suscite sugestões e ações significativas para a sua vida.

Gadotti (2003, p. 2I) afirma que 
O papel da educação não pode ser confundido apenas com sua ligação fundamental e intrínseca com o conhecimento e, muito menos, com a pura transmissão de informações. Educação no mundo globalizado tem função menos leccionadora e mais organizadora do conhecimento.

O professor não é a única variável a interferir no processo da aprendizagem, mas é quem possui um papel muito importante para o desenvolvimento dos indivíduos das escolas. O professor que conhece os processos de evolução da escrita e detecta a hipótese a qual seu aluno se encontra, poderá propiciar-lhe conscientemente um melhor desenvolvimento. Segundo Emília Ferreiro: "Conhecer quais são esses processos de compreensão infantil dota o alfabetizador de um valioso instrumento para identificar momentos propícios de intervenção nesse processo" (FERREIRO, 1993, p. 25).

Conhecer as hipóteses utilizadas pelos alunos na construção da escrita favorece ao professor aplicar atividades que possibilitam avanços nas aprendizagens. Quanto melhor o professor entender o processo de construção do conhecimento, mais eficiente será seu trabalho. O professor deve ser um parceiro na aprendizagem de seus alunos. É fundamental que o professor crie um ambiente que facilite situações de diálogo e participação no qual seja possível que os alunos se sintam seguros, sem medo de errar. Para o estabelecimento desse ambiente o professor deve mostrar a confiança a seus alunos a partir do respeito mútuo, acreditando sinceramente nas capacidades dos mesmos e os incentivando com atividades desafiadoras que favoreçam a observação do processo.

Outro fator o qual se acredita ser fundamental para um melhor desempenho do aluno é o afeto, pois se sentindo seguro e valorizado o aluno não terá medo de errar, testando sua hipótese certamente poderá avançar no processo de construção do conhecimento. Atualmente fala-se muito da importância de se partir das experiências das crianças, de aceitar os erros que a criança produz, rever os métodos de alfabetização, de conhecer os processos de aquisição da língua escrita. O professor não pode deixar seu papel de mediador do processo pedagógico para ser apenas um conferencista que não estimula a pesquisa e o esforço se contentando com a transmissão de soluções já prontas.

A aprendizagem da leitura constitui uma relação simbólica entre o que se deve e diz, com o que se vê e lê. A leitura deve ser vista, igualmente, como um fenômeno duplo que envolve o compreender e a compreensão. É necessário fazer uma distinção entre ler e aprender a ler. Ler é estabelecer uma comunicação com textos, por meio da busca da 
compreensão. A aprendizagem da leitura constitui uma tarefa permanente que se enriquece com novas habilidades na medida em que se manejam adequadamente estes textos cada vez mais complexos. Por isso, a aprendizagem da leitura não se restringe ao primeiro ano de vida escolar. Atualmente, sabe-se que aprender a ler é um processo que se desenvolve ao longo de toda a escolaridade e de toda a vida (ZILBERMAN, 1988, p. 13). Segundo Ferreiro e Teberosky (I99I, p. 26): “[...] as crianças antes da sua entrada para a escola, já tem construções mentais sobre a leitura e a escrita e não se limitam a receber passivamente os conhecimentos".

De acordo com as autoras, a criança que chega à escola já é um "bom" leitor do mundo. Desde muito nova começa a observar, a antecipar, a interpretar e a interagir, dando significado aos seres, objetos e situações que a rodeiam. Ela utiliza estas mesmas estratégias de busca de sentido para compreender o mundo letrado. Ainda para as autoras, essa aprendizagem natural da leitura deve ser considerada pelo professor e incorporada as suas estratégias de ensino, com o fim de melhorar a qualidade desse processo contínuo iniciado no momento em que a criança é capaz de captar e atribuir significado as coisas do mundo. Assim, a ação de ler o mundo em que a criança enfrenta progressivamente numerosa e variados textos.

\footnotetext{
O trabalho de leitura, na escola, tem por objetivo levar o aluno a análise e à compreensão das ideias dos autores e buscar no texto os elementos básicos e os efeitos de sentido, é importante que o leitor se envolva, se emocione e adquira uma visão dos vários materiais portadores de mensagem presentes na comunidade em que se vive (ZILBERMAN, i988, p. I8).
}

A leitura acontece quando se produz o sentido e quanto mais informação, experiências de leituras anteriores, mais consciência na formação de sentido terá o leitor, pois além de que se encontram nas linhas é preciso atender também as entrelinhas. Só quem lê interpreta, questiona, estabelece julgamentos do que pode e deve fazer, exercendo plenamente a sua cidadania. Só quem lê pode mudar a realidade para melhor. A língua portuguesa faz parte das disciplinas obrigatórias no currículo do Ensino Fundamental e Médio. Sem o conhecimento da mesma é impossível que o aluno consiga compreender o meio em que vive e até discernir as tomadas de decisões que a vida nos impõe. 
A leitura está basicamente relacionada ao fato de possibilitar ao ser humano o seu sucesso, e a tomada de consciência da sua importância torna-se aí essencial para que se valorize muito a leitura. Um bom educador valoriza a leitura e age conscientemente cobrando do aluno a leitura diária em casa, idas à biblioteca, jornais, revistas, livros, diversos etc. A leitura não poderá ser uma ação mecânica, pelo contrário, deverá ser cobrada, exigindo do aluno tudo que foi lido, incentivando-o sempre para que tomem gosto pela mesma. E para compreendê-la no todo, há necessidade que se aprenda a ler e se leia muito. Agindo assim o aluno não encontrará dificuldades em outras matérias, pois todas dependem da leitura. $\mathrm{O}$ ato de ler deve acompanhar o ser humano a vida toda. Isso é muito importante.

No entanto, a leitura escolar é uma das formas de se fazer LEITURA, pois dentre os alunos que não gostam de ler na sala de aula, estão aqueles que usam a leitura na vida diária, como vendedor ou lendo jornais, revistas, listas de preços etc. A escola deve oferecer condições para que as interações aconteçam. Assim, o aluno avança na construção do conhecimento significativo através da contextualização e da interdisciplinaridade.

\section{INTERAÇÃO COM OS EDUCANDOS SOBRE O ATO DE LER}

É importante que a leitura se constitua como uma prática social de diferentes funções, pelas quais estudantes podem perceber que precisam ler não somente para compreender, mas também para se comunicarem, adquirir conhecimentos, ampliar os horizontes em relação ao mundo e as questões inerentes ao seu bem estar social. Configura-se, então, como uma necessidade básica na vida de cada uma que pode ser produtiva para enriquecer as relações interpessoais dentro do seu grupo ou até mesmo no mercado de trabalho.

Diante dessa necessidade presente no meio educacional, diversos programas do Governo Federal tentam trazer para a escola uma oportunidade de se constituir na prática um leitor realmente compreensivo e crítico, e traz para as salas de aulas obras que colocam o aluno em contato com materiais de qualidade, que se bem explorados resultam positivamente, como é o caso do programa Literatura em minha casa, que distribui entre os alunos do ensino fundamental, livros de literatura infanto-juvenil que contemplam peças de teatro, poesias, contos, novelas e narrativas de autores consagrados de nossa literatura. 
Também organizações não governamentais se engajam em distribuição de livros e tenta atribuir à leitura um caráter lúdico, visando prender a atenção do alunoleitor. Todas as contribuições nesse âmbito são válidas, desde que não desvie a leitura do seu objetivo principal que é a compreensão e a estimulação da criatividade e da criticidade do leitor. Em geral, os textos apresentados nos livros didáticos fogem da realidade social na qual nossos alunos estão inseridos, tornando-se de difícil compreensão. Por meio da reforma do Ensino Médio e a divisão das disciplinas por áreas, surgiu também a tentativa de contextualizar o livro didático de Língua Portuguesa. Tal tentativa afastou ainda mais o educando do uso habitual desse material, pelo fato de que para entender os conteúdos precisa ler cada vez mais, e, aí chega no ponto chave que boa parte dos jovens não gostam de ler, e torna a coisa cada vez mais difícil. Para Luckesi (1994, p. I44):

[...] o livro didático, de forma alguma, deve ser instrumento descartável no processo de ensino. Ele é um instrumento importante, desde que tem a possibilidade de registrar e manter, com fidelidade e permanência a mensagem. $\mathrm{O}$ que está escrito permanece escrito; não é tão perecível quanto à memória viva.

Tomando como base o ensino e aprendizagem da leitura crítica, bem como a formação do leitor competente, o livro didático não pode ausentar-se desse processo, principalmente pelo fato de ser, em alguns casos, o único material a esse respeito que o aluno dispõe em casa e até mesmo na escola. Cabe, então, ao professor, utilizar o mais significativamente possível os textos abordados por este tipo de livro, considerando o que o aluno sabe e o que pode aprender com a contribuição desse documento. $O$ desenvolvimento de ações que viabilizem a formação do leitor crítico é fundamental, principalmente entre os jovens que cursam essa modalidade de ensino, pelo fato de poderem estar adquirindo mais segurança na leitura e também tomando gosto pelo ato de ler. Para tanto, é fundamental que o professor sirva de modelo, mostrando-se leitor ativo e compreensivo, para que possa mediar o processo de interação entre seus alunos e o universo letrado que envolve a leitura.

Podemos afirmar que formar um leitor crítico não é tarefa fácil, entretanto fica claro que se trata de algo extremamente significativo para o aluno. As mudanças no currículo do ensino médio contemplam disciplinas que abordam conteúdos, que dão significado e reflexos na sua vida cotidiana. Assim, a leitura contribui não somente para a 
formação intelectual do indivíduo, mas para a formação moral e cultural, sendo um conhecimento de base para todos os outros que pode vir a adquirir ao longo da vida, além de servir também de entretenimento e prazer. É função de a escola ensinar esse tipo de leitura sob estes paradigmas.

$\mathrm{Na}$ verdade, o que se almeja alcançar do trabalho com a leitura crítica no ensino médio é um leitor que seja capaz de ultrapassar os limites pontuais de um texto e incorporá-lo reflexivamente no seu universo de conhecimento de forma a levá-lo a melhor compreender seu mundo e seu semelhante. Partindo do ponto de vista de que "[...] o verbo ler mão suporta imperativo" (PENNAC, 1993, p. 13), a leitura não deve ser encarada nem pelo professor nem pelo aluno como uma obrigação, um dever, e sim como uma atividade prazerosa. Para tanto, o professor deve demonstrar paixão pela mesma e apresentá-la como fundamental para a formação intelectual dos educandos. Para Kleiman (1998, p. 5I):

[...] o leitor proficiente faz escolhas baseando-se em predições quanto ao conteúdo do livro. Essas predições estão apoiadas no conhecimento prévio, tanto sobre o assunto (conhecimento enciclopédico), como sobre o autor, a época da obra (conhecimento social, cultural, pragmático) o gênero (conhecimento textual). Daí ser necessário que todo programa de leitura permita ao aluno entrar em contato com um universo textual amplo e diversificado.

A leitura é uma atividade que está presente na escola em todas as atividades que envolvem as disciplinas do currículo. Lê-se para ampliar os limites do próprio conhecimento. Por isso, precisa se fazer presente na vida do estudante, não como algo paralelo do seu ensino-aprendizagem, mais como alguma coisa essencial para o desenvolvimento cognitivo dos estudantes e principalmente dentro de um contexto real de leitura e análise de textos, para que o ato de ler possa passar a fazer sentido para os educandos. Pois, "Heráclito nos ensina que ninguém desce duas vezes no mesmo rio, pois suas águas mudam constantemente" (NASCIMENTO; SOLIGO, 1999, p. 40).

\section{CONCLUSÃO}

Podemos perceber que a leitura exercitada corretamente possui vasta função social na medida em que é parte axial de uma consciência crítica que tem como fruto a formação intelectual de homens críticos e formadores de opinião, participativos no processo de evolução social. Nesse sentido, abordamos aspectos que ajudam e dificultam o 
ato de ler de forma eficaz fazendo um comparativo entre as causas e as consequências de uma leitura passiva, nociva aos leitores, mas de conformidade com os anseios das classes dominantes.

De qualquer forma, sejamos otimistas ou pessimistas, apocalípticos ou integrados, podemos tomar como base que uma nova leitura do mundo é necessária, que a imensa maioria não está preparada para ou não sabe como fazer essa leitura, e que esse ato de ler não será isento de ideologia. E mais ainda, não haverá o conforto de uma leitura "totalizante": teremos que conviver tolerantemente com diferentes leituras do mundo. O aluno, mentalmente, com o uso da leitura das histórias infantis, simultaneamente reconhece e diferencia os ambientes ora contados na história, como suas influências sobre os personagens. Sabe-se que a leitura dos quadrinhos leva a criança ao mundo extremamente mágico e magnífico onde ela se transporta quase que totalmente a vivenciála e até mesmo imagina interagi-la.

Retrocedendo ao surgimento e consequente aplicação da literatura infantil e seu público (as crianças) e fazendo um paralelo entre esse período, suas minúcias observadas e os dias de hoje, foi que certificamos que seu ideal imaginário ainda possui uma constante preocupação em manter-se a cada dia inovando e despertando a fantasia de nossas crianças, porém há ainda muito a ser percorrido para conseguir provar que ela, a literatura infantil, é um meio primordial para o alcance de uma formação mister social, político e cultural da criança tanto numa Instituição Escolar quanto no ambiente familiar. Tem-se escrito e comentado muito que as crianças de hoje leem menos textos verbais e veem mais televisão e jogam com o auxílio do computador sem um valor literário crítico.

Todas as novas tecnologias têm o seu espaço. As crianças são muito receptivas às novidades. Portanto, o livro não deixa, mesmo assim, de ter o seu lugar e sua importância. É sabido que o texto estimula a imaginação, provoca reflexões pessoais, favorece a meditação, enriquece o patrimônio verbal e a cultura geral do leitor. A imagem, pelo contrário, suprime a interpretação e convida a contemplação passiva por falta de orientação de leitura. 


\section{REFERÊNCIAS}

BRASIL. Secretaria de Educação Fundamental. Parâmetros Curriculares Nacionais: Língua Portuguesa. Brasília, 1997.

BRASIL. MINISTÉRIO DA EDUCAÇÃO. Secretaria de Educação Fundamental. Programa de Alfabetização de Professores Alfabetizadores. Janeiro, 20oI.

BRASIL. PCN. Parâmetro Curricular Nacional. Regras para ensinar a Língua Portuguesa no ensino fundamental e médio. Brasília, Distrito Federal: Editora do Governo federal, 1998.

FREIRE, Paulo. A importância do ator de ler. São Paulo: Pontes, 1987.

FREIRE, Paulo; BETO, Frei. Essa escola chamada vida: depoimentos ao repórter Ricardo Kotscho. São Paulo: Ática, 1996.

FREIRE, Paulo. Pedagogia da Indignação: Cartas pedagógicas e outros escritos. São Paulo: UNESP, 2003.

FERREIRO, Emília. O processo de ensino e o desenvolvimento integral do educando. São Paulo: Cortez, I993.

FERREIRO, Emília; TEBEROSKY, Ana. Psicogênese da língua escrita. Tradução: Diana Myriam Lichtenstein, Liana Di Marco e Mário Corso. Porto Alegre: Artes Médicas Sul, i991.

FERREIRO, Emília. A Leitura e a Escrita: Sistema de Comunicação Humana. São Paulo: Atual, i99i.

GADOTTI, Moacir. A relação professor-aluno no processo ensinoaprendizagem. São Paulo: Romana, 2003.

KLEIMAN, Ângela. Oficina de leitura. Teoria e Prática. Campinas: Pontes e Editora da UNICAMP (1993).

MINAS GERAIS. Série Lições de Minas. Tempo Escolar: Hora de Refletir e Organizar. Belo Horizonte. Secretaria de Estado da Educação de Minas Gerais. v. 3. Nov. I999.

SOARES, Magda. TV Escola. $\mathrm{N}^{\circ}$ 24. Agosto/setembro. 20oI.

TEBEROSKY, Ana. Psicopedagogia da língua escrita. Tradução: Beatriz Cardoso. Petrópolis, RJ: Vozes, 2oor.

ZILBERMAN, Regina. (Org) Leitura Perspectivas Interdisciplinares. São Paulo, Editora Ática, 1998. 